\title{
Marketing para recursos humanos: comunicaciones internas para la marca empleador
}

\author{
Marketing for human resources: internal communications for the employer brand
}

\author{
Ximena Márquez Hernández ${ }^{a}$
}

\begin{abstract}
:
The Human Resources is considered as an auxiliary or support area, currently is priority area for managers, companies are increasingly controlled of the importance of human talent in an organization, including employees in projects it is more practicable to achieve the defined objectives, highlighting the importance of effective and comprehensive internal communication for the different generations that collaborate in the company, the employer brand must motivate and inspire, communication being the pillar of this value, proposing an internal communication strategy aligned with the current needs.
\end{abstract}

Keywords:

Organizational Marketing, Human Resources, Internal Communications, Employer Brand

\section{Resumen:}

El área de Recursos Humanos se consideraba como un área auxiliar o de apoyo, actualmente es como un área prioritaria para los directivos, las empresas están cada vez más conscientes de la importancia del talento humano en una organización, al incluir a los colaboradores en los proyectos es más factible el alcance de los objetivos definidos, resaltando la importancia de una comunicación interna eficaz y comprensiva para las diferentes generaciones que colaboran en la empresa, la marca empleador debe motivar e inspirar, siendo la comunicación el pilar de este valor, proponiendo una estrategia de comunicación interna alineada a las necesidades actuales.

\section{Palabras Clave:}

Marketing organizacional, Recursos humanos, Comunicaciones internas, marca empleadora.

\section{Introducción}

Marketing para Recursos humanos: comunicaciones internas para la marca empleador es un libro publicado en el mes de mayo del año 2017 con 226 páginas dividido en dos partes, la primera parte consta de 6 capítulos partes y aborda temas orientados a comunicaciones internas de la marca, en la segunda parte por medio de casos de vivencias organizacionales ejemplifica la teoría planteada para aumentar la comprensión del tema.

Capítulo I Estrategias para una comunicación interna eficaz

$x$

Considerar a la comunicación como un elemento importante es un punto de partida esencial, las organizaciones priorizan la ejecución de las actividades para el alcance de los objetivos que se apeguen a la planificación prevista, excluyendo el cómo comunicar, en el pasado se consideraba que las áreas que conformaban una empresa estaba separadas por sus responsabilidades así como el control de la autoridad en cada gerencia, la planeación así como ejecución se centraba en algunos elementos de la empresa, actualmente en los negocios los colaboradores deben tener la capacidad de innovar y analizar en equipo posibles soluciones para las dificultades.

Capítulo II La comunicación interna y su impacto en la marca empleador.

Destaca la importancia de identificar el concepto que las marcas han generado en sus propios empleados, en la vida interna de las organizaciones, de acuerdo con una investigación desarrollada por los autores del libro donde se aprecia una clara diferencia entre los medios y los fines,

a Autor de Correspondencia, Universidad Autónoma del Estado de Hidalgo, Email: ma238609@uaeh.edu.mx 
los valores positivos, comunicación con reglas claras, las mayores diferencias se aprecian en las emociones que impactan directamente en el proyecto de vida de los colaboradores, un empleado orgulloso con compromiso recomendara la organización.

Capítulo III Eficacia de los diversos medios de comunicación interna

Se considera que una comunicación es eficaz cuando logra su objetivo alcanzado las metas establecidas por el emisor del mensaje, sin embargo, aunque el objetivo se encuentra establecido depende del receptor que este se cumpla., cuando se cuenta con evidencia de que se entendió el mensaje realizando la acción deseada.

Capítulo IV Coherencia entre el hacer y decir como pilar de la marca empleador

Previo a la comunicación se debe de tener clara la visión de lo que la organización es para las personas, analizando lo que se deba cambiar o mantener, una vez definidos estos lineamientos de comunicación se deben mantener en el día a día comunicando el mensaje desde los lideres siendo honesto con la información a compartir cuidando de no asumir que los logros de la empresa se sepan por los colaboradores si no se establece una estrategia de comunicación.

Capítulo V Comunicación y subjetividad: el desafío de escucharnos

Cuando se trata de información se relaciona con datos, los números tienen fiabilidad, pero las palabras tienen un contexto humano haciendo necesaria la decodificación del mensaje donde surge la brecha de la percepción con la de los paradigmas donde los silencios pueden hablar más fuerte que las palabras, este hecho resalta la importancia de la comunicación cuando se tiene que enfrentar a la subjetividad.

Capítulo VI Como gestionar las comunicaciones internas en momentos de crisis

Los colaboradores tienen un rol como voceros de la organización, la comunicación influye en diversos aspectos del clima laboral, no se tiene una única definición de que es una crisis de comunicación, pero claramente son sucesos imprevistos que se pueden presentar en los diferentes tipos de organizaciones dañando el desempeño, todas las empresas han tenido crisis en algún momento en diferentes grados, la comunicación debe retroalimentarse así los colaboradores explican su versión cuidando la comunicación interna, la estrategia de comunicación debe considerar acciones online-offline, una comunicación planificada permite flexibilidad y adecuación.

Casos de vivencias organizacionales

La mejor manera de entender es hacer, combinando la teoría con experiencias, profesionales de diferentes industrias comparten sus relatos enriqueciendo el conocimiento de la lectura.

\section{Casos de vivencias organizacionales}

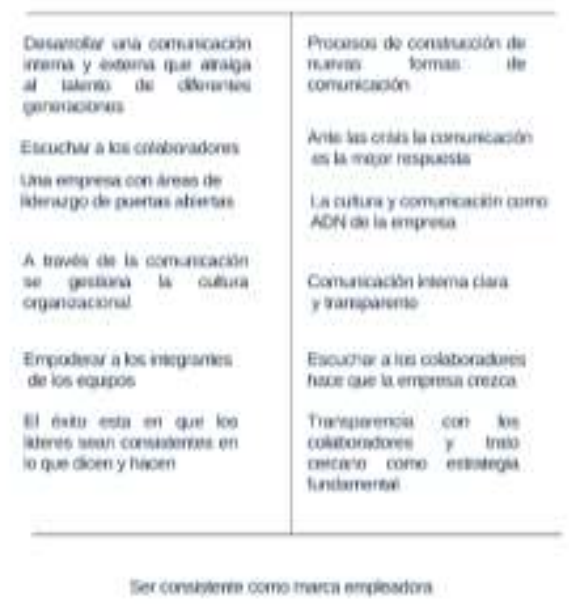

Figure 1. Fuente: elaboración propia

\section{Referencias}

[1] Linardi, A. y Cortina, M, (2017) Marketing para recursos humanos: Comunicaciones internas para la marca Empleador. Granica 1era edición. Buenos Aires. 